\title{
New Refractory
}

\section{Hung Arch}

\section{Reduces Furnace Failures}

$\mathbf{E}$ VERY steel mill operator must get more and more production out of existing equipment. When a furnace is down for repairs, operations are curtailed with no possibility of recovering lost production. One of the primary causes of furnace shutdowns is suspended arch failures. Suspended arch failures are not entirely caused by expansion of the refractories themselves. The method of arch suspension failing to localize refractory expansion results in mechanical spalling.

To minimize arch failures, the arch must be sufficiently flexible in movement to overcome possible heating and twisting of steel supports, and casting warpage, and to absorb and localize refractory expansion. To minimize replacement time, and, because of the ever-increasing shortage of experienced masons, repairs must be made with the fewest number of men and manhours.

Several years ago, the George P. Reintjes Co., Kansas City, Mo., started to sell arches to the steel industry. Considerable time was spent studying arch requirements of open hearth, soaking pit, and many other types of steel mill furnaces. As a result, Reintjes developed a refractory pendulum hung suspended arch which incorporated all of the desirable features which the steel mill engineers and operators wanted.

This arch was so flexible that it could be attached to the existing steel framework of most any furnace with practically no structural changes even though the framework was warped or twisted to such an extent that it could no longer support the arch for which it was originally designed.

On one of the first installations, this double hung arch was put to a crucial test. The pit cover was dropped off the jacks as it was being lowered into position. In dropping, the frame was twisted, leav-

Fig. 1. When a tile is dropped in place, it is automatically aligned. ing one corner $4 \mathrm{in.}$ lower than the opposite corner, yet not a single refractory or casting was damaged in any way. The pit was under fire within two days after the accident. For the four pit covers, each having approximately $250 \mathrm{sq} f t$ of arch, the total erection mason labor required per pit was less than $20 \mathrm{hr}$. The erection of the arch is shown in Fig. 1, which also shows how the U-bolts supporting the tubing extend through the lower flange of the overhead beams. If the beams become warped or sag in service, the arch can be re-aligned simply by turning a nut. The secret of the low erection cost lies not only in the pendulum hung action, but also because the horizontal " $S$ " locks the tiles in position, requiring no straight edges or bracing to align the arch.

Tests were conducted to determine the strengths of the upper and lower tiles. The breaking point for the lower and upper tiles, both 3 in. wide, was 675 $\mathrm{lb}$, the equivalent of $2700 \mathrm{lb}$ per lineal $\mathrm{ft}$ of arch. In some tests, the breaking point per unit was over $900 \mathrm{lb}$.

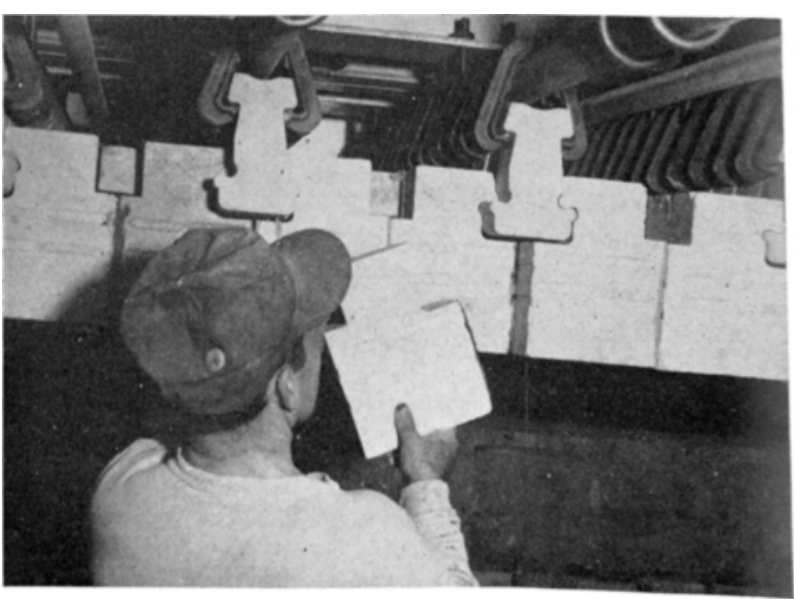

